\title{
LXXV. On the construction and effects of the pneumatic tinder-box
}

\section{Le Bouvier Desmortiers}

To cite this article: Le Bouvier Desmortiers (1812) LXXV. On the construction and effects of the pneumatic tinder-box , Philosophical Magazine Series 1, 40:176, 424-431, DOI: $10.1080 / 14786441208638263$

To link to this article: http://dx.doi.org/10.1080/14786441208638263

册 Published online: 27 Jul 2009.

Submit your article to this journal $₫$

Џll Article views: 2

Q View related articles $₫$ 
It has been often suspected, that the contraction of volume produced in the pure earths by heat is owing to the expulsion of water combined with them. The following fact scems to confirm this suspicion, and offers a curious phænomenon.

Zircona, precipitated from its solution in muriatic acid by an alkali, and dried at a temperature below $300^{\circ}$, appears as a white powder, so soft as not to scratch glass. When heated to $700^{\circ}$ or $800^{\circ}$, water is suddenly expelled from it, and notwithstanding the quantity of vapour formed, it becomes at the moment red hot. After the process, it is found harsh to the feel, has gained a tint of gray, its parts cohere together, and it is become so hard as to scratch quartz.

LXXV. On the Construction and Effects of the Pneumatic Tinder-Box. By Le Bouvier Desmortiers*.

$T_{H E}$ inflammation of spunk + in the Pneumatic Tinderbox, by the compression of air alone, is a phænomenon with which chance, the father of discovery, has lately enriched natural philosophy. Many have reasoned on its cause; which some consider to be caloric, others electricity; but no one, that I know of, has attempted to support his opinion by experiments. Without bias for any hypothesis, I have made some researches on the construction and effects of the pneumatic tinder-box, the results of which shall be the subject of the present paper. In the first part, I shall consider what relates to the structure of the instrument ; in the second, I shall give an account of the experiments that tend to the discovery of the cause of its effects.

I. The first construction of these tinder-boxes was a little faulty, in the piston being commonly 18 or 20 lines long. This was said to be necessary, that the air might not escape when the piston was in action; for, if there were any point not accurately fitted to the inside of the tube, the air escapes, and the spunk does not kindle.

The goodness of the instrument does not depend on the length of the piston, but on the accuracy with which it fills the bore of the tube; with a tube well bored and a piston

* Journal de Phys. tom. Ixvii.

+ Spunk is prepared from agaric, which is first beiled in water; beaten well when dry; steeped in a strong solution of saltpetre; and lastly dried in an oven. If the solution of nitre be too strong, the agaric is loaded with this salt, which retards its inflammation. 
of six lines, the air will no more pass than with a piston of twenty. Accordingly, for a tube of six inches I have reduced the piston to six lines, which adds an inch to the column of air, and diminishes the friction two-thirds, so that the effect of the tinder-box is more certain, and it is more easily used. With a lit:le dexterity you may kindle the spunk by holding the tube in one hand and pushing the piston with the other, without being obliged to rest it on a table, or any other solid body. Mr. Dumotiez, a skilful maker of philosophical instruments, is so fully convinced of the advaintage of short pistons, that he now makes them of these dimensions*.

They should be employed also in the syringes of air guust, of fountains acting by compressed air, of the apparatus for artificial mineral waters, of fire-engines, which are worked with so much labour, and even of air-pumps. As the shortening the piston is an advantage to the pump, we obtain a greater effect with less labour, and in a shorter time, than with long pistons.

It is essential, too, that the instrunent does not leak at the part where the spunk is placed, because there the transient action of inflammation takes place, and a slight emission of air would prevent the effect. But this effect is produced, though the piston does suffer the air in the tube to pass it. To satisfy myself of this, I made the following experiment, at which they who have seen it were greatly surprised.

In the length of the piston I made a groove a quarter of a line broad. The spunk took fire as betore. Three other grooves were added successively, opposite one another, so as to divide the piston into equal parts; and still the spunk-took fire. When the grooved piston is moved backward and forward in the tube, the air may be heard entering or issuing out; and the friction is so slight, that the effect of the instrument is easily obtained by pushing it with the hand. This kind of piston would be preferable to those that fit accurately, if a solid substance were employed, hard enough to resist the continual friction of the air passing through the grooves, if I may be allowed the expression. The gronves iil leather pistons soon alter their shape, and spread so as to allow the air to pass it in too large quantity.

- Mr. Gill, of St. James's-street, London, makes these instruments of still smaller dimeusions. -Evir.

$t$ In the air guns of Germany, which are the best we know, the piston of the syringe is extremely short.

The 
The piston with four grooves acting very well, I made one with a single groove, of dimensions equal to the other four, and what I foresaw actually took place : there was no inflammation. The following are the reasons of this difference.

The extremity of the grooved piston exhibits the area of a circle, the periphery of which touches the interior edge of the grooves. The column of air contained in the tube rests almost wholly on this base. Only the parts corresponding to the grooves, that are continued through the length of the piston, communicate with the external air. When the piston is pushed with sufficient velocity to kindle the spunk, the parts of the column corresponding to the grooves rush into them with equal velocity; but the friction they experience in passing through such narrow tubes occasions a resistance to their passage, a kind of choking, that suffers only a part to escape, while the column resting on the area of the piston is pushed entirely toward the extremity of the tube, where the spunk to be kindled lies.

In the piston with a single broad groove, the area of the circle, on which the column of air rests, is much smaller, consequently the column itself is less. The resistance the air experiences in passing through the groove is next to nothing; for we hear no noise on moving the piston backward and forward; and as air expands in all directions, when the piston is moved, the column resting on the area of the circle, resting at the same time laterally on that which answers to the groove, it recedes from all the points of contact, and flows entirely through the channel it finds open. It is so true, that it wholly flows ont, that the piston, when it touches the extremity of the tube, remains there; while with other pistons a sufficieut quantity of air is retained to occasion a spring and repel them.

I think it proper to say a word or two on the quality of the spunk. The driest, softest, and least impregnated with nitre should be chosen. In that of the best quality, a picee will not always be found equally good throughnut. Some contains a great deal of nitre, and is kindled with more difficulty. This may be known by the cool taste it leaves on the tongue; or by kindling it: for when it has taken fire the nitre melts and sometimes throws out sparks, that may be dangerous when they spirt out of the instrument, particularly if made with a cock. As it is usual to blow on the spunk, to try whether it be kindled, a spark may be thrown 
thrown from it into the eye. This painful accident once happened to me.

They who imagine that electricity kindles the spunk, consider these sparks as an incontrovertible proof of their o;inion. I think they are mistaken in this case; yet I must not conceal a fact communicated to me by Mr. VeauDelaunay, which seems to confirm this opinion, of which the is a partisan. Out of twelve times, when be operated with the instrument without any spunk in it, he saw sparks emitted three times. There are strong reasons, however, for suspecting that electricity is not the cause of the inflammation here. These I shall give in the second part of this paper, concluding the present with an important observation on the construction of pistons.

If we could find an elastic substance sufficiently compact to be turned in a lathe, we should have perfect pistons, that would spring and adapt themselves to the inequalities of the tube, without suffering a bubble of air to escape. I have made some with caoutchouc, softened before the fire, in order to give it a degree of elasticity more obedient to the inequalities of the tube. But on attempting to turn it in a larhe, it bent under the tool. Even the edge of a razor wuuld not take bold of it; so that the piston remained uneven and almost ragged, and yielded like soft wax under the fingers. In this imperfect state it so far prevents the air from escaping, that a column of three inches is sufficient to kindle the spunk; but after a few strokes of the piston the heat dilates it to such a degree, that it cannot be moved without considerable force. If a drop of oil be put on it, it moves easily; but this soon spoils the instrument; for the oil dissolves the caoutchouc, and forms a varnish, which, as the piston grows hot, makes it adhere still more strongly to the sides of the tube.

Might not these inconveniences be avoided, by arming the piston rod with caoutchonc, and covering this with leather? If this process succeeded, it might be applied with advantage to all sorts of pumps.

II. To attain, if possible, a knowledge of the principle of inflammation in the pneumatic tinder-box, four things are to be considered - the materials of the tube, the matter contained in the tube, the materials of the piston, and the friction. Among the materials of the piston I include the grease, with which it is coated, to nake it more more easily, and render it fitter to intercept the passage of the air.

In examining the question whether the spunk be kindled by electricity, I consider, 
Ist, That no part of the instrument is insulated; and that insulation is a peoessary condition for producing sensible electricity with any of the machines we know. I say machines that we know, because the animal electricity, that manifests itself without insulation, is an exception to our mechanical means, and cannot here be taken into consideration.

$2 \mathrm{dly}$, The friction of the piston, which is a greasy body, against a metallic substance, is not calculated to produce electricity.

3dly, Experience demonstrates, that, unless during storms, the atmosphere seldom exhibits any signs of electricity at the height we breathe it; and that we must search for them with instruments in a more elevated reginn, or when electric clouds are passing over our heads. How then shall we estimate the infinilely small quantity of electric matter in a cubic inch of air, or even less, which the instrument contains ?

4thly, It is not without great difficulty that we can kindle spunk with strong electric sparks. I have discharged a large jar on spunk strewed with powdered resin, and it has remained unkindled, though the resin caught fire, and burned entirely away.

As long as the instrument was made with metallic substances only, we were obliged to confine curselves to the exterior marks of inflammation alone, without being able to assign the true cause, or at least furnish proofs of it. For to guess, is not sufficient in natural philosophy; we must demonstrate, in order to give to facts that degree of certainty which befits science; and this we cannot do here, without seeing what passes at the very point of inflammation.

The means are very simple. Nothing is necessary but to substitute a glass for a metal tube. Those found in the shops being too slight, I applied to Mr. Laurent, the inventor of glass flutes, requesting him to procure me tubes of a similar quality. This artist, as much distinguished by his civility as by his talents, furnished me with three, which I fitted up. The first, eight inches long by eight lines in diameter, did not kindle the spunk. The second, nine inches long by six lines and tbree-quarters in diameter, kindled it completely. This being destroyed by accident, I tried the third, eight inches long by seven lines in diameter, which succeeded equally well.

When the instrument is made to act, and the spunk kindles, we see a bright flash, that fills the capacity of the 
tube; and this light is so much the more vivid, in proportion as the compression is more rapid. If the compression be less powerful, the spunk does not kindle; but we perceive in the upper part of the tube a light vapour, that falls in undulations on the piston. When this has disappeared, if we draw back the piston, the vapour will re-appear, as long as there is any air in the tube. These effects may be produced several times in succession, merely by pushing the piston with the hand. This vapour is so thin and diaphanous, that it is not perceptible in a strong light. It requires a sort of twilight to see it well.

But whence arises this vapour, and what is its nature? Assuredly it is not furnished by the materials of the instrument; it can only proceed, therefore, from what it contains, from the atmospheric air. Now, according to the present state of our knowledge, the air contains only nitrogen, oxygen, and a very small portion of carbonic acid; all gasitorm substances, which are kept in this state by the great quantity of caloric that penetrates them, and are consequently heavier than it*. But in compressing. the air contained in the tube, what is the substance that must first give way? Is it not that which is lightest, the caloric, that general solvent, that principle of fluidity and volatilization, which gives wings even to metals to raise themselves in the air? Is then the vapour in question caloric, rendered visible by approximation of its particles, which are compressed by the surrounding air, as air becomes visible in passing through liquids? This idea, which I am far from presenting as a thing proved, acquires more probability from the following experiments.

I substifuted hydrogen for common air, and the vapour showed itself as before; but the spunk did not take fire. With carbonic acid gas, and with nitrogen, the effects were the same. The latter, which conțained a little nitrous gas, gave a somewhat deriser vapnur. Oxygen, lightly compressed, yielded a vapour more rare and transient than that of the common air. It had scarcely fallen on the piston, when it rebounded and disappeared. When I compressed

- The air likewise, in its ordinary state, contains twelve grains of water in a cubic foot. This small quantity of water, reduced to the proportion of the quantity of air contained in the apparatus, contributes nothing to its effect; for the heat produced by the friction could at most reduce it to vapour, and in this state it would not kindle the spunk. If the vapour seen in the tube were water in a state of expansion, when it fell on the surface of the piston it would condense there, and appear in the state of a liquid. But the surface of the piston always remains dry, though on moving it the vapour appears and disappears several times. 
oxygen with a proper force for producing inflammation, the spunk, which commonly takes fre only at the anterior part, was alinost burned: yet for this experiment I used a copper instrument, the piston of which lost air so much, that it would no longer kindle spunk with common air.

Perhaps it will be said that the vapour caine from the greasy malter on the piston, which adheres to the sides of the tube; and that it is expanded by the heat produced by the friction. To this 1 answer, in this case, ist, The rapour should not show itself before the greasy matter is de: posited on the sides of the tube; yet it appears at the first stroke of the piston, before the tube becomes greasy. ally, It should show itself below the piston; in the part which the piston has left; but, on the contrary, it always shows itself ahove. $3 \mathrm{dly}$, There is no vapour, when the piston loses much air, if the friction be ever so rapid. 4thly, The rapour should be more apparent, when the piston exerts its friction throughout the whole length of the tube, than when it is confined to a small part of its upper extremity; yet the reverse frequently happens. 5thly, When the air is entirely decomposed no nore vapour appears, but it shows itself again, if ever so little fresh air be introduced.

As it was essential to ascertain whether the vapour did not contain an acid principle, I fastened to the surface of the piston, with a little green wax, a piece of auslim dipped in infision of litmus, and afterwards dricd. After twenty strokes of the piston the colour was not changed. I put on a second piece of muslin larger than the first, and the edges of which were loose. This burned all round; withont the colour of the rest being altered. Lastly, a third piece, which was wet, experienced no change of colour.

From these experments it follows, that no acid principle is developerl; that all aëriform substances, as well as common air, produce a light vapour: that no other gas, except oxygen and common air, kindles the spunk: that oxygen produces a much nore powerful combustion than common air, consequently oxygen acts an important part in the infammation : that as it can exert its action only when set frée by the decomposition of the conmon air, of which it constitutes a fourth part, it follows, that the air contaiued in the tube is decomposed by the simple force of compression: that the vapour produced is not owing to the oxygen, since it shows itself equally in gases that contain no oxygen: that this vapour is the effect of some agent common to all gases : and that we may presume it 
is caloric itself, rendered visible by the sudden approximation of its parts in a small space, where it rises to a temperature that is increased in the oxygen so as to kindle the spunk*.

I am equally induced to believe, since the air (and it is the same with all gases) is decomposed by rapid compression, that the luninous meteors frequently perceived in hurricanes are not always the effects of electricity. I have observed several times, on these occasions, that Saussure's atmospheric electrometer affords no signs of any. I will mention a particular instance, as it occasioned me no less surprise than damage.

In the beginuing of the year 1803 , bcing at my country seat, toward evening a violent wind arose, which continued increasing for two hours to such a degree, as to blow down about sixfy trees of prodigious size and height in an ornamental plantation. It threw them one upon another in a row, and some of them were broken off. Those that were torn up by the roots brought up the earth with them to the distance of fifteen feet. The clouds flew with extreme rapidity, and I saw flashes of light from them. I raised my electrometer, armed with its conductor two feet long, but the balls still continued in contact.

LXXVI. Mr. Hume's Remarks on Dr. Roger's Reply. To Mr. Tilloch.

Sir, $D_{k}$. Roget having confessed that I did make use of the words "or any other alkali," the question at issue between us becomes more simple; it is merely this, Whence are the distinctions between sulphate of copper and nitrate of silver, which prove that one of these salts is totally different from the other, when applied for the detection of arsenic?

That there is a total difference, especially when ammonia is employed, has been asserted by Dr. Rnget;-that there is no such dissimilarity in the application of these twa tests, to support such an opinion, I shall now endearour to prove.

- It sometimes happens, that the spunk is turned black without kindling. In this case, as well as when it is kindled, if we drawiback the piston in the tube, a dense vapour, that may be smelt, issues out, which is not of the ga ne nature as the former. 'I hat shows itself before the inflammation: this always succeeds it. That is the principle of the inflammation : this is a product furuished by the combustion of the spunk, of which it has the smell. 